\title{
Bacterial Contamination of Intraocular Lenses: the Source of the Bacteria
}

\author{
S. R. SPENCER, S. F. DEALLER, ${ }^{*}$ P. D. A. HASSETT, N. J. TODD, ${ }^{*}$ P. M. \\ HAWKEY, ${ }^{*}$ B. A. NOBLE \\ Leeds
}

\begin{abstract}
Summary
In order to investigate potential sources for the bacterial contamination of intraocular lenses, specimens were taken for culture from a variety of sites. A swab from the lid margin, the operating room air, an intraocular lens which was allowed to rest on the eye, and the sodium hyaluronate were cultured during routine intercapsular lens implant surgery on 31 patients. Positive cultures were obtained from six intraocular lenses. Subtyping by three independent methods showed that isolates from five of these lenses were indistinguishable from bacteria cultured from the air. In the case of the sixth lens a bacterial isolate from the lid margin matched with that from the lens. Staphylococcus epidermidis was cultured from four lenses; Staphylococcus haemolyticus was also isolated from one of these four lenses and the remaining two lenses produced isolates of Straphylococcus aureus.
\end{abstract}

There has been a great deal of interest over the past few years in the role of human 'commensal' bacteria in nosocomial infections. Coagulase-negative staphylococci (CNS) are the major cause of sepsis following prosthetic surgery of all types. This includes joint replacement, vascular grafts, cardiac valve replacement, CSF shunts, all forms of intravenous catheters, (especially long term central lines), and intraocular lens implantation. ${ }^{1-4}$

While infection of many of these prostheses can have catastrophic results leading to death of the patient or at the least removal of the prosthesis, in intraocular lens surgery it has been suggested that endophthalmitis caused by CNS may be managed with retention of the lens. ${ }^{3.5,6}$ Although this may be true, the development of endophthalmitis following cataract surgery is rightly feared and requires prompt intervention for the best visual outcome. Infection caused by CNS and the antibiotics required to erradicate it can cause significant reduction in post operative visual function.

In other types of surgery using prosthetic material and on intravenous lines it has been well demonstrated that CNS, once attached to medical grade plastics, adhere strongly and become embedded in an extracellular mucoid glycocalyx or slime film which renders them resistant to phagocytosis and antibiotics. ${ }^{7-9}$ There may be a long delay in diagnosis and recurrence is common and hard to detect.

This study looks at the possible source of the organisms which adhere to intraocular

From: Department of Ophthalmology, The General Infirmary at Leeds, Great George Street, Leeds.

*Department of Medical Microbiology, University of Leeds, 1 Thorseby Place, Leeds.

Correspondence to: Mr. S. R. Spencer, Department of Ophthalmology, The General Infirmary, Great George Street, Leeds LS1 3EX 
lenses. Suggestions are made which should reduce the contamination rate of intraocular lenses and therefore the rate of postoperative endophthalmitis.

\section{Method}

Thirty-one patients undergoing routine intercapsular cataract surgery with bag fixated polymethylmethacrylate lenses with prolene loops were included in the study. All patients gave informed consent. The study was approved by the hospital ethical committee.

Normal routine management was followed from admission to discharge. The only extra procedures that were undertaken were a swab from the upper lid margin prior to skin preparation and the application of an intraocular lens to the ocular surface prior to cataract incision.

Chloramphenicol drops were administered with the dilating drops one hour prior to surgery. A subconjunctival injection of betamethasone $2 \mathrm{mg}$ and gentamicin $20 \mathrm{mg}$ was given at the end of surgery. This was standard procedure for all patients undergoing cataract surgery on this unit and we endeavoured to make as little change as possible to normal procedure.

Four samples were taken for culture.

\section{(1) The lid margin swab}

Before skin preparation with aqueous povidone iodine a cotton wool swab moistened with balanced salt solution was rubbed firmly along the upper lid margin and stored in a sterile container. In the laboratory, the swab was plated onto $5 \%$ horse blood agar (Oxoid, Basingstoke) and incubated in air at 37 degree $\mathrm{C}$ for 48 hours.

\section{(2) The air sample}

After skin preparation and towelling a battery driven centrifugal air sampler (RCS type, Biotest Ltd, Solihull) with a fresh agar slab was switched on and directed over the operation site for exactly 60 seconds. Incubation conditions were the same as above.

\section{(3) The intraocular lens}

When the patient had been fully prepared for surgery and just prior to the corneal incision an intraocular lens was opened as if for implantation and placed on the limbus for five seconds. It was then placed on an agar plate (5\% horse blood agar, Oxoid Ltd., Basingstoke). This was cultured at 37 degree $\mathrm{C}$ in air for 48 hours.

\section{(4) The sodium hyaluronate}

At the end of the operation the sodium hyaluronate was aspirated as is our normal procedure. For the study it was divided into equal halves. One half was injected into a blood culture bottle (Oxoid, Signal System). The other half was stored at -70 degree $C$. The blood culture bottle was incubated at 37 degree $\mathrm{C}$ for ten days. At 48 hours and ten days it was subcultured onto chocolate agar plates incubated in $5 \% \mathrm{CO}_{2}$ and onto blood agar plates incubated anaerobically for 48 hours.

All colonies from the intraocular lenses, lid swabs and sodium hyaluronate, and all staphylococci from the air samples were subcultured onto blood agar and stored at -70 degree $\mathrm{C}$ in glycerol/citrate cryoprotective medium as described previously. ${ }^{10}$

Staphylococci are identified by biotype. This method distinguishes various species and each species may have a few different biotypes. Different strains of staphylococci may be further separated by their antibiogram and plasmid analysis. The antibiogram is a means of comparing separate isolates of the same bacterial species by examining the Minium Inhibitory Concentrations (MICs) of a range of antibiotics. Because coagulese negative staphylococci carry a very large range of plasmids, plasmid analysis, which compares the plasmids from different isolates, is an extremely accurate way of identifying identical strains. ${ }^{11,12}$

Bacterial isolates grown from the lid swabs, intraocular lenses and sodium hyaluraonate were typed and compared with isolates from the air samples. Coagulase negative staphylococci were typed by biotyping (API Staph), antibiogram, and plasmid analysis. We used the ultra rapid method for plasmid analysis described by Bennett et al. ${ }^{13}$ The Staphylococcus aureus isolates were typed using a standard phage typing method. ${ }^{14}$ 


\section{Results}

Bacteria were grown from six intra ocular lenses $(19.4 \%)$. Coagulase negative staphylococci were present on four lenses and there were two lenses which were contaminated with Staphylococcus aureus. Table I shows the organisms which were grown, the source of the match and the typing method used to confirm the match.

In order to identify matching strains of bacteria at least eight colonies from each source were typed. The lenses only produced single colonies except in case 31 in which there were two.

Although five patients developed postoperative inflammation with a transient fibrinoid exudate (cases 14,15,18,19,20) none of these were in our group with positive lens cultures. It is also of note that the patient with Staphylococcus aureus isolated from the sodium hyaluronate did not develop post operative inflammation.

\section{Discussion}

Using a method similar to that described by Vafidis et al. ${ }^{15}$ we have demonstrated a bacterial contamination rate of the same order as they did for their control group of lenses, exposed to operating room air alone. By culturing the air and subjecting the isolates from the air and the lenses to plasmid analysis we have been able to demonstrate that bacteria of identical strains were present in both

Table I Baceteria derived from the lens

\begin{tabular}{|c|c|c|c|}
\hline Case & Bacterium & $\begin{array}{l}\text { Source } \\
\text { of match }\end{array}$ & Method \\
\hline 7 & Staph. epidermidis & air & $\begin{array}{l}\text { biotype } \\
\text { antibiogram } \\
\text { plasmid }\end{array}$ \\
\hline 2 & Staph. epidermidis & air & $\begin{array}{l}\text { biotype } \\
\text { antibiogram } \\
\text { plasmid }\end{array}$ \\
\hline 25 & Staph. epidermidis & swab & $\begin{array}{l}\text { biotype } \\
\text { antibiogram } \\
\text { plasmid }\end{array}$ \\
\hline 31 & $\begin{array}{l}\text { Staph. epidermidis } \\
\text { Staph. haemolyticus }\end{array}$ & $\begin{array}{l}\text { no match } \\
\text { air }\end{array}$ & $\begin{array}{l}\text { biotype } \\
\text { antigiogram } \\
\text { plasmid }\end{array}$ \\
\hline 17 & Staph. aureus & $\begin{array}{l}\text { air, } \\
\text { hyaluronate }\end{array}$ & phage \\
\hline 6 & Staph. aureus & air, swab & phage \\
\hline
\end{tabular}

specimens in five out of six contaminated cases. Vafidis et al., undertook neither of these procedures.

Christensen et al., ${ }^{16}$ showed that species definition, biotyping, antibiograms and phage typing reduces the probability of classifying two strains of coagulase negative staphylococci as identical by chance to $\mathrm{p}=0.014$. Although we did not use phage typing for the coagulase negative isolates it is clear that plasmid analysis should provide an even more certain means of identifying separate strains.

In two cases the bacterium on the lens matched the isolate from the margin swab and one of these also matched with the air isolate. It is therefore possible that the organisms in the air may have originated from the patient's skin or that the patients lids became contaminated from the air. In this case we feel that the former is more likely.

The isolates from the air and lens in case 17 matched with a bacterium cultured from the sodium hyaluronate. There is no means of knowing whether the staphylococcus gained entry to the eye as a result of contamination of the intraocular lens which was implanted in this case or whether it was introduced during another part of the surgical procedure. However, this finding strongly supports the argument that bacteria from the air may easily be introduced into the eye during surgery.

All our lenses were ethylene oxide sterilised dry pack lenses. These lenses carry an electrostatic charge which attracts skin squames from the operating room air. Wetting the lenses with saline or water discharges them leaving no residual charge and should therefore reduce the risk of contamination from the air. (Unpublished data).

Endophthalmitis occurs following cataract surgery in between $0.086 \%$ and $0.5 \%$ of operations. ${ }^{17,18}$ These figures are from very large series but are now somewhat old and predate the routine use of intraocular lenses and the recognition of CNS as a cause of endopthalmitis. It is possible that many cases of coagulase negative staphylococcal endopthalmitis go unrecognised and are treated as chronic uveitis.

There is also a well recognised fibrinoid reaction which may develop following intra- 
ocular lens surgery usually between 48 and 36 hours after the operation. (Five cases in this series.) This may occur in non-diabetics and is not related to prolonged hypotony or any unusual trauma during the operation. It is transient and disappears quickly with increased topical steroid leaving no sequelae. Although there are many reasons why this may occur including exfoliation, syndrome ${ }^{19}$ the individuals reaction to trauma, irrigating solutions and drugs, it might also be the eye's reaction to a subinfective dose of microorganisms.

Chronic inflammation after intraocular lens implantation or inflammation which begins after YAG laser capsulotomy-may be due to the anaerobic gram-positive bacillus Propionibacterium which can become sequestered in cortical lens matter..$^{20-22}$ In our study anaerobic cultures were only continued for 48 hours. This may not be long enough to grow this bacterium. In the clinical setting any case of persistent inflammation ought to have anaerobic cultures of aqueous, vitreous or retained lens matter performed before it is labelled toxic lens syndrome or phacoanaphylactic uveitis.

It is interesting that lenses placed in broth inoculated with Staphylococcus epidermidis have a maximum concentration of organisms along the prolene loops after incubation for several days. ${ }^{23}$ All our positive lens cultures were from the PMMA optic. It may be that the PMMA optic picks up the organism from the air or ocular surface and that in fluid culture it preferentially adheres to the prolene loops.

The first reports of coagulase negative staphylococcal endophthalmitis confirmed by paracentesis were in the early $1970 \mathrm{~s}^{24}$ and now these organisms are implicated in up to $60 \%$ of cases of post operative endophthalmitis. ${ }^{3,25}$ The rise in incidence not only parallels an increased awareness of the organism as a pathogen but also closely parallels the increased use of intraocular lenses. Indeed, it has been elegantly demonstrated that these organisms are largely non-pathogenic when implanted under the skin but produce a suppurative reaction when injected in the presence of a piece of intravenous catheter material buried beneath the skin. ${ }^{26}$
While it has been well demonstrated that the flora of the conjunctival sac is important in the development of most of the more serious cases of bacterial endophthalmitis we believe that the operating room air is likely to be the source of the organism when coagulase negative staphylococcal endophthalmitis occurs and the air may also be the source of a proportion of the cases of Staphylococcus aureus infections.

Since the majority of cases of endophthalmitis are due to these organisms we believe that closer attention should be paid to reducing the number of circulating squames in ophthalmic theatres. This has already been achieved with marked success in orthopaedic theatres. ${ }^{27}$

Although ultra clean air systems of this type may be impractical in ophthalmology the least we can do is to consider ways of reducing bacterial contamination of lenses and this means reducing the time from opening the intraocular lens packet to implantation, discharging the lens immediately the packet is opened, reducing the distance the lens is moved through the air after opening and avoiding contact with the conjunctiva or lids during implantation.

Our thanks to Pharmacia who provided the lenses used in this study.

\section{References}

${ }^{1}$ Davis AJ: Coagulase negative staphylococcal infections. Editorial. Br Med J 1985, 290: 1230-1.

${ }^{2}$ Lowy FD, Hammer SM: Staphylococcus epidermidis infections. Ann Intern Med 1983, 99: 834-9.

${ }^{3}$ Weber DJ, Hoffman KL, Thoft RA, Sullivan Baker A: Endophthalmitis following intraocular lens implantation: report of 30 cases and review of the literature. Rev Infect Dis 1986, 8(1): 12-20.

${ }^{4}$ Ficker L, Meredith TA, Wilson LA, Kaplan HJ, Kozarsky AM: Chronic bacterial Endophthalmitis. Am J Ophthalmol 1987, 103: 745-8.

${ }^{5}$ Hopen G, Mondino BJ, Kozy D, Lipkowitz J: Intraocular lenses and experimental bacterial endophthalmitis. Am J Ophthalmol 1982, 94: 402-7.

6 O'Day DM, Jones DB, Patrinely J, Elliott JH: Staphylococcus epidermidis endophthalmitis. Visual outcome following non invasive therapy. Ophthalmology 1982, 89: 354-60.

${ }^{7}$ Christenson GD, Simpson WA, Bisno AL, Beachey EH: Adherence of slime-producing strains of Staphylococcus epidermidis to smooth surfaces. Infect Immun 1982, 37: 318-26.

${ }^{8}$ Christenson GD: The confusing and tenacious coag- 
ulase negative staphylococci. Adv Intern Med 1987, 32: 177-92.

${ }^{9}$ Christenson GD, Baddour LM, Simpson WA: Phenotypic variation of Staphylococcus epidermidis slime production in vitro and in vivo. Infect Immun 1987, 55: 2870-7.

${ }^{10}$ Hawkey PM, Bennett PM, Hawkey CA: Cryptic plasmids in hospital isolates of Providencia Stuarts'. J Med Microbiol 1984, 18: 277-84.

11 Parisi JT and Hecht DW: Plasmid profiles in epidemiologic studies of infections by Staphylococcus epidermidis. J Infect Dis 1980, 141: 637-43.

12 Archer GL, Karchmer AW, Vishniavsky N, Johnston JL: Plasmid-pattern analysis for the differentiation of infection from non infecting Staphylococcus epidermidis. J Infect Dis 1984, 149: 913-20.

${ }^{13}$ Bennett PM, Heritage J, Hawkey PM: An ultrarapid method for the study of antibiotic resistance plasmids. J Antimicrobial Chemotherapy 1986, 18: 421-4.

${ }^{14}$ Parker MT: Phage typing of Staphylococcus aureus. In: Methods in Microbiology (JR Norris and DW Ribbons eds.), 1972, Vol 7b: 1-28 Academic Press, London \& New York.

15 Vafidis GC, Marsh RJ, Stacey AR: Bacterial contamination of intraocular lens surgery. $\mathrm{Br} \mathrm{J}$ Ophthalmol 1984, 68: 520-3.

${ }^{16}$ Christensen GD, Parisi JT, Bisno AL, Simpson WA, Beachey EH: Characterisation of clinically signficant strains of coagulase negative staphylococci. Clin Microbiol 1983, 18: 258-69.

${ }_{17}$ Allen HF and Mangiaracine AB: Bacterial endophthalmitis after cataract extraction II Incidence in 36000 consecutive operations with special reference to preoperative topical antibiotics. Trans Am Acad Ophthalmol Otolaryngol 1973, 77: 581-8.

${ }^{18}$ Christy NE and Lall P: Postoperative endo- pthalmitis following cataract surgery. Arch Ophthalmol 1973, 90: 361-6.

${ }^{19}$ Olivius EOP, Nordell SI, Walinder PE: Fibrinoid reaction after extracapsular cataract extraction and its relationship to exfoliation syndrome. A prospective study. Eur J Implant RefSurg 1989, 1: 5-8.

${ }^{20}$ Meisler DM, Palestine AG, Vastine DW, Demartini DR, Murphy BF, Reinhart WJ, Zakov ZN, McMahon JT, Cliffel TP: Chronic Propionibacterium endophthalmitis after extracapsular cataract extraction and intraocular lens implantation. Am J Ophthalmol 1986, 102: 733-9.

${ }^{21}$ Piest KL, Kincaid MC, Apple DJ, Tetz MR, Roberts WA, Price FW: Localised endophthalmitis: a newly described cause of the so-called toxic lens syndrome. J Cat Refract Surg 1987, 13: 498-510.

${ }^{22}$ Tetz MR, Apple DJ, Price FW, Piest KL, Kincaid MC, Bath PE: A newly described complication of Neodymium-YAG laser capsulotomy: Exacerbation of an intraocular infection. Arch Ophthalmol 1987, 105: 1324-5.

${ }^{23}$ Dilly PN and Holmes Sellors PJ: Bacterial adhesion to intraocular lenses. J Cat Refract Surg 1989, 15: 317-20.

${ }^{24}$ Valenton MJ, Brubaker RF, Allen HF: Staphylococcus epidermidis (albus) endophthalmitis. Report of two cases after cataract extraction. Arch Ophthalmol 1973, 89: 94-6.

${ }^{25}$ Puliafito CA, Baker AS, Haaf J, Foster CS: Infectious endopthalmitis. Review of 36 cases. Ophthalmology1982, 89: 921-9.

${ }^{26}$ Christensen GD, Simpson WA, Bisno AL, Beachey $\mathrm{EH}$ : Experimental foreign body infections in mice challenged with slime-producing Staphylococcus epidermidis. Infect Immunol 1983, 40: 407-10.

${ }^{27}$ Lidwell OM, Lowbury EJL, Whyte W, Blowers R, Stanley SJ, Lowe D: Effect of ultraclean air in operating rooms on deep sepsis in the joint after total hip or knee replacement: a randomised study. Br Med J 1982, 285: 10-14. 